\title{
A Comprehensive Mapping of the Druggable Cavities within the SARS-CoV-2 Therapeutically Relevant Proteins by Combining Pocket and Docking Searches as Implemented in Pockets 2.0
}

\author{
Silvia Gervasoni ${ }^{1}{ }^{(}$, Giulio Vistoli $^{1}$, Carmine Talarico ${ }^{2}\left(\mathbb{D}\right.$, Candida Manelfi $^{2}$,

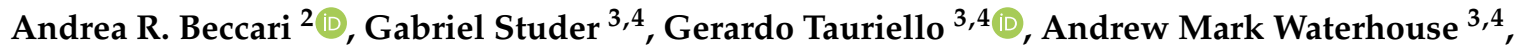 \\ Torsten Schwede ${ }^{3,4}\left(\mathbb{D}\right.$ and Alessandro Pedretti ${ }^{1, *}$ (i) \\ 1 Dipartimento di Scienze Farmaceutiche, Università degli Studi di Milano, Via Mangiagalli, 25, \\ I-20133 Milano, Italy; silvia.gervasoni@unimi.it (S.G.); giulio.vistoli@unimi.it (G.V.) \\ 2 Dompé Farmaceutici SpA, Via Campo di Pile, I-67100 L'Aquila, Italy; carmine.talarico@dompe.com (C.T.); \\ candida.manelfi@dompe.com (C.M.); andrea.beccari@dompe.com (A.R.B.) \\ 3 Biozentrum, University of Basel, Klingelbergstrasse 50-70, CH-4056 Basel, Switzerland; \\ gabriel.studer@unibas.ch (G.S.); gerardo.tauriello@unibas.ch (G.T.); \\ andrew.waterhouse@unibas.ch (A.M.W.); torsten.schwede@unibas.ch (T.S.) \\ 4 SIB Swiss Institute of Bioinformatics, Biozentrum, University of Basel, Klingelbergstrasse 50-70, \\ CH-4056 Basel, Switzerland \\ * Correspondence: alessandro.pedretti@unimi.it; Tel.: +39-02-503-19332
}

Received: 15 June 2020; Accepted: 14 July 2020; Published: 21 July 2020

\begin{abstract}
Background: Virtual screening studies on the therapeutically relevant proteins of the severe acute respiratory syndrome Coronavirus 2 (SARS-CoV-2) require a detailed characterization of their druggable binding sites, and, more generally, a convenient pocket mapping represents a key step for structure-based in silico studies; (2) Methods: Along with a careful literature search on SARS-CoV-2 protein targets, the study presents a novel strategy for pocket mapping based on the combination of pocket (as performed by the well-known FPocket tool) and docking searches (as performed by PLANTS or AutoDock/Vina engines); such an approach is implemented by the Pockets 2.0 plug-in for the VEGA ZZ suite of programs; (3) Results: The literature analysis allowed the identification of 16 promising binding cavities within the SARS-CoV-2 proteins and the here proposed approach was able to recognize them showing performances clearly better than those reached by the sole pocket detection; and (4) Conclusions: Even though the presented strategy should require more extended validations, this proved successful in precisely characterizing a set of SARS-CoV-2 druggable binding pockets including both orthosteric and allosteric sites, which are clearly amenable for virtual screening campaigns and drug repurposing studies. All results generated by the study and the Pockets 2.0 plug-in are available for download.
\end{abstract}

Keywords: SARS-CoV-2; pocket search; pocket druggability; docking simulations; virtual screening; blind docking

\section{Introduction}

The exploration of the potential binding cavities within a given target protein represents a key step among the computational tasks, which follow the target identification [1]. After the experimental resolution or the in silico modeling of the target structure, such a mapping enables the identification of the most relevant binding sites for which virtual screening simulations or de novo rational design 
should allow the identification of promising hits. Clearly, a medium-size protein can have a large number of cavities, which show different shapes (holes, clefts, pores, tunnels, etc.) as well as different roles [2]. Therefore, the first crucial step in the cavity mapping is the recognition of those cavities that are accessible and can have a role in modulating the protein activity. Yet again, not all the potentially interesting cavities can be effectively engaged by interacting ligands. While playing a role in protein activity, some cavities are indeed unable to generate stable complexes with (at least) small drug-like molecules due to their structural, physicochemical, or electronic properties. This fact led to the concept of pocket druggability, the evaluation of which should allow the identification of those cavities for which the hit identification should be reasonably productive [3].

Hence, it comes as no surprise that a remarkable number of computational approaches have been proposed in the last years with a view to mapping the cavities within a given protein structure and to evaluating the resulting druggability. They comprise methods based on Voronoi tessellation [4], grid search [5], surface analysis [6], void sphere clustering [7] or they can involve various combinations of these [8]. Moreover, the increasing number of experimentally resolved protein structures allows a markedly more accurate validation of these methods [9]. By using a purposely collected cavity database, a recent benchmarking analysis compared some well-known approaches for mapping the protein cavities and revealed that FPocket and GaussianFinder are those offering the best performances, with FPocket being able to identify the highest number of correct cavities [10].

Even though the above-discussed methods to detect protein cavities also include an evaluation of their druggability, other methods are specifically focused on the druggability analysis of the found pockets. They can be based on the physicochemical and structural local properties of the cavities or the comparison with homologous proteins or the sole sequence analysis. Often, these methods combine various kinds of information and develop their predictions by using machine learning approaches [11].

To the best of our knowledge and although very often the detected pockets are further evaluated by performing preliminary docking simulations using reference ligands, the combination of pocket searches with systematic docking analyses as an automatic tool to find and to prioritize the target cavities has never been proposed. Therefore, the present study describes Pockets 2.0, a plug-in implemented in the VEGA ZZ suite of programs [12], which combines the FPocket method, chosen due to its notable performances (see above) with docking simulations as performed by PLANTS [13] or by AutoDock/Vina programs [14]. The overall Pockets 2.0 performances were then assessed by comprehensively analyzing a dataset comprising all non-structural or therapeutically promising SARS-CoV-2 proteins for which orthosteric and allosteric binding sites, as well as some potential ligands, were derived by an extensive literature search focused on the homologous proteins. The dataset includes both resolved structures and homology models, thus allowing potential differences in the Pockets 2.0 performances between them to be revealed.

\section{Results}

\subsection{Overview of the Available Data on SARS-CoV-2 Binding Pockets}

Before applying the here proposed method to identify and to assess potentially druggable binding pockets within the SARS-CoV-2 proteins, a careful literature search was performed. When the binding pockets were not directly identifiable by the available structures, they were derived by comparing the considered SARS-CoV-2 proteins with resolved homologous proteins. This study had two primary objectives: 1) finding putative orthosteric and allosteric pockets by which to assess the performances of the proposed method and 2) finding potential ligands (substrates, inhibitors or modulators) to be used as probes during docking simulations. Not to mention that the here collected information is relevant per se, since it affords a better understanding of the catalytic mechanism and (if present) of the allosteric modulation for the analyzed enzymes and can guide the corresponding docking simulations. Hence, this section reports the relevant information acquired during this literature analysis for some 
relevant SARS-CoV-2 proteins. All the information collected during such a comprehensive literature analysis is compiled in Table 1.

Table 1. Orthosteric and allosteric binding sites for the therapeutically relevant protein targets as derived from the literature search.

\begin{tabular}{|c|c|c|c|c|c|c|c|}
\hline Protein & Source $^{a}$ & Function & $\begin{array}{l}\text { Reference } \\
\text { Protein }\end{array}$ & PDB Id & Site & Ligand ${ }^{c}$ & Ref. \\
\hline 3CL-PRO & See Table 2 & protease & $-^{\mathrm{b}}$ & $-^{\mathrm{b}}$ & orthosteric & $3 W L$ & {$[15,16]$} \\
\hline \multirow{5}{*}{ N-Protein } & \multirow{5}{*}{ 6M3M 6VYO } & \multirow{5}{*}{ Nucleocapsid protein } & \multirow{5}{*}{$\begin{array}{l}\text { HCoV-OC43 } \\
\text { N-NTD }\end{array}$} & $4 \mathrm{LMC}$ & \multirow{5}{*}{ orthosteric } & C5P & \multirow{5}{*}{ [17] } \\
\hline & & & & 4LM9 & & $5 \mathrm{GP}$ & \\
\hline & & & & 4LM7 & & U5P & \\
\hline & & & & 4LI4 & & AMP & \\
\hline & & & & $4 \mathrm{KXJ}$ & & P34 & \\
\hline Nsp3 & 6W02 & $\begin{array}{l}\text { ADP ribose } \\
\text { phosphatase }\end{array}$ & - & - & orthosteric & $\mathrm{ADP}$ & $* * * d$ \\
\hline Nsp6 & DN & $\begin{array}{l}\text { Membrane-spanning } \\
\text { protein }\end{array}$ & $\begin{array}{l}\text { No experimental } \\
\text { information apart } \\
\text { from } \\
\text { mutants analysis }\end{array}$ & - & allosteric & K22 & [18] \\
\hline \multirow[t]{2}{*}{ Nsp9 } & \multirow[t]{2}{*}{$6 \mathrm{~W} 4 \mathrm{~B}$} & \multirow[t]{2}{*}{ Replicase } & $\begin{array}{l}\text { Coronavirus } \\
\text { NSP9 }\end{array}$ & 1QZ8 & orthosteric & $\mathrm{SO} 4$ & [19] \\
\hline & & & $\begin{array}{l}\text { Type } 2 \text { rhinovirus } \\
3 \mathrm{C} \text { protease }\end{array}$ & 1CQQ & orthosteric & AG7 & [20] \\
\hline \multirow{4}{*}{ Nsp12 } & \multirow{4}{*}{ 7BV2 } & \multirow{4}{*}{$\begin{array}{l}\text { RNA-dependent RNA } \\
\text { polymerase (RdRp) }\end{array}$} & - & - & orthosteric & F86 & $* * *$ \\
\hline & & & Hepatitis C RdRp & 2BRL & allosteric1 (thumb) & $\mathrm{POO}$ & [21] \\
\hline & & & $\begin{array}{l}\text { Hepatitis C NS5B } \\
\text { polymerase }\end{array}$ & 2HAI & alllosteric2 (thumb) & PFI & [22] \\
\hline & & & $\begin{array}{l}\text { Hepatitis C NS5 } \\
\text { polymerase }\end{array}$ & 3НHK & allosteric3 (palm) & $77 \mathrm{Z}$ & [23] \\
\hline \multirow[t]{2}{*}{ Nsp13 } & \multirow[t]{2}{*}{$\mathrm{HM}$} & \multirow[t]{2}{*}{ Helicase } & $\begin{array}{l}\text { RNA-Dependent } \\
\text { ATPase Upf1 }\end{array}$ & 2XZL & orthosteric & ADP-ALF & [24] \\
\hline & & & $\begin{array}{l}\text { Hepatitis C virus } \\
\text { NS3 protein }\end{array}$ & $4 \mathrm{~B} 75$ & Allosteric & $4 \mathrm{VA}$ & [25] \\
\hline Nsp14 & $\mathrm{HM}$ & Methyltransferase & SARS-CoV & $5 \mathrm{C} 8 \mathrm{~S}$ & orthosteric & SAH, G3A & [26] \\
\hline Nsp15 & 6W01 & Endoribonuclease & SARS-CoV & $2 \mathrm{H} 85$ & orthosteric & U3M & [27] \\
\hline Nsp16 & $\begin{array}{l}6 \mathrm{WKS} \\
6 \mathrm{~W} 4 \mathrm{H} \\
\end{array}$ & Methyltransferase & - & - & orthosteric & SAM, GTA & $* * *$ \\
\hline PL-pro & $6 \mathrm{~W} 9 \mathrm{C}$ & Papain-like protease & SARS-CoV & 3E9S & orthosteric & TTT & $* * *$ \\
\hline Spike & Xray with ACE2 & Viral entry glycoprotein & - & - & Protein-protein interaction & YMZ & {$[28-36]$} \\
\hline
\end{tabular}


Table 2. Results of the pocket analysis as performed by Pockets 2.0 on the therapeutically relevant protein targets. The first part of the Table includes data concerning the overall search (such as the source of the analyzed protein, the probe ligand and the number of found pockets), while the second part comprises data concerning the search for the correct pocket. In detail, the Table reports how the correct pocket was ranked by FPocket and PLANTS alone and by consensus score, which combines both searches. The volume and the ChemPLP score for the correct pocket are also listed.

\begin{tabular}{|c|c|c|c|c|c|c|c|c|}
\hline \multirow{2}{*}{ Protein } & \multicolumn{3}{|c|}{ Protein Data } & \multicolumn{5}{|c|}{ Data for the Search of the Correct Pocket } \\
\hline & Source/ID & Ligand & $\begin{array}{c}\mathrm{N} \\
\text { Pockets }\end{array}$ & $\begin{array}{l}\text { Rank by } \\
\text { Fpocket }\end{array}$ & $\begin{array}{l}\text { Rank by } \\
\text { PLANTS }\end{array}$ & $\begin{array}{l}\text { Rank by } \\
\text { Consensus }\end{array}$ & $\begin{array}{c}\text { Volume } \\
\left(\AA^{3}\right)\end{array}$ & $\begin{array}{l}\text { ChemPLP } \\
\text { (kcal/mol) }\end{array}$ \\
\hline \multirow{14}{*}{ 3CL-PRO } & $5 R 7 Y$ & $3 W L$ & 16 & 1 & 1 & 1 & 3604.93 & -76.15 \\
\hline & $5 \mathrm{R} 7 \mathrm{z}$ & $3 W L$ & 16 & 1 & 1 & 1 & 4246.06 & -73.85 \\
\hline & $5 \mathrm{R} 80$ & $3 W L$ & 20 & 2 & 2 & 1 & 1833.23 & -76.48 \\
\hline & $5 \mathrm{R} 81$ & $3 W L$ & 17 & 1 & 1 & 1 & 3141.06 & -80.27 \\
\hline & $5 \mathrm{R} 82$ & $3 \mathrm{WL}$ & 19 & 1 & 4 & 1 & 3989.84 & -68.23 \\
\hline & $5 \mathrm{R} 83$ & $3 W L$ & 21 & 1 & 1 & 1 & 4079.17 & -77.59 \\
\hline & $5 \mathrm{R} 84$ & $3 W L$ & 21 & 1 & 1 & 1 & 2562.02 & -80.88 \\
\hline & 6LU7 & $3 W L$ & 14 & 1 & 1 & 1 & 4239.62 & -77.83 \\
\hline & 6MN2 dimer & $3 W L$ & 80 & 1 & 1 & 1 & 3344.72 & -86.30 \\
\hline & $6 \mathrm{M} 03$ & $3 W L$ & 24 & 3 & 3 & 3 & 2175.81 & -69.70 \\
\hline & $6 \mathrm{Y} 2 \mathrm{E}$ & $3 W L$ & 18 & 1 & 4 & 1 & 2629.29 & -75.02 \\
\hline & $6 \mathrm{Y} 2 \mathrm{~F}$ & $3 W L$ & 20 & 1 & 1 & 1 & 2581.33 & -77.61 \\
\hline & $6 \mathrm{Y} 2 \mathrm{G}$ & $3 W L$ & 16 & 2 & 3 & 2 & 5074.55 & -75.78 \\
\hline & $6 \mathrm{Y} 84$ & $3 W L$ & 20 & 1 & 2 & 1 & 3068.30 & -73.94 \\
\hline Nsp3 & 6W02 & APR & 6 & 2 & 1 & 1 & 2247.84 & -119.05 \\
\hline \multirow{2}{*}{ Nsp6 } & DN & \multirow{2}{*}{ K22 } & 25 & 3 & 1 & 1 & 2364.82 & -75.26 \\
\hline & DN & & 27 & 4 & 1 & 1 & 3692.30 & -76.86 \\
\hline Nsp9 & 6W4B & AG7 & 13 & 2 & 3 & 1 & 2740.53 & -97.41 \\
\hline \multirow{3}{*}{ Nsp12-Nsp7-Nsp8 } & \multirow{3}{*}{ 7BV2 trimer } & ATP (ortho) & \multirow{3}{*}{79} & 1 & 2 & 1 & 4397.28 & -94.18 \\
\hline & & $\begin{array}{c}\text { POO/ PFI } \\
\text { (allo) }\end{array}$ & & 2 & 1 & 1 & 3545.24 & -97.80 \\
\hline & & $77 Z$ (allo) & & 1 & 4 & 2 & 4397.28 & -85.22 \\
\hline \multirow{2}{*}{ Nsp13 } & \multirow{2}{*}{$\mathrm{HM}$} & ADP (ortho) & \multirow{2}{*}{40} & 3 & 2 & 2 & 4359.36 & -79.98 \\
\hline & & 4VA (allo) & & 5 & 10 & 5 & 2526.96 & -74.28 \\
\hline \multirow{3}{*}{ Nsp14-Nsp10 } & \multirow{3}{*}{ HM dimer } & SAH & \multirow{3}{*}{49} & 2 & 9 & 4 & 5307.98 & -80.25 \\
\hline & & SAM & & 2 & 2 & 1 & 5307.98 & -88.09 \\
\hline & & G3A & & 2 & 1 & 1 & 5307.98 & -119.09 \\
\hline \multirow{2}{*}{ Nsp15 } & 6W01 hexamer & U3P & 170 & 5 & 3 & 1 & 2792.58 & -80.39 \\
\hline & 6VWW dimer & U3P & 52 & 6 & 1 & 3 & 2275.76 & -81.75 \\
\hline \multirow{4}{*}{ Nsp16-Nsp10 } & \multirow{2}{*}{ 6WKS dimer } & SAM & \multirow{2}{*}{63} & 1 & 8 & 1 & 4772.88 & -88.43 \\
\hline & & GTA & & 1 & 1 & 1 & 4772.88 & -118.80 \\
\hline & \multirow{2}{*}{ 6W4H dimer } & SAM & 31 & 1 & 1 & 1 & 3243.06 & -87.81 \\
\hline & & GTA & & 1 & 2 & 1 & 3243.06 & -112.33 \\
\hline N-protein & $6 \mathrm{M} 3 \mathrm{M}$ & C5P, 5GP, U5P, & 7 & 3 & 2 & 2 & 1252.56 & -66.69 \\
\hline & $6 \mathrm{VYO}$ & AMP, Р34 & 7 & 3 & 3 & 3 & 1961.99 & -70.57 \\
\hline PL-Pro & 6W95 & TTT & 23 & 3 & 2 & 1 & 2134.23 & -94.17 \\
\hline & 6LZG dimer & & 56 & 2 & 2 & 1 & 4792.66 & -80.66 \\
\hline SPIKE-ACE2 & $6 \mathrm{M} 0 \mathrm{~J}$ dimer & YMZ & 58 & 1 & 5 & 1 & 4407.92 & -74.29 \\
\hline & 6M17 hexamer & & 275 & $\begin{array}{c}1 \\
11\end{array}$ & $\begin{array}{l}1 \\
1\end{array}$ & $\begin{array}{l}1 \\
2\end{array}$ & 3767.99 & -81.79 \\
\hline & 6VW1 dimer & & 61 & 1 & 2 & 1 & 4920.74 & -77.78 \\
\hline & ctly Identified Po & kets & & 20 & 18 & 30 & & \\
\hline & t Pockets Rankec & as \#2 & & 9 & 10 & 5 & & \\
\hline & t Pockets Rankec & as \#3 & & 6 & 5 & 3 & & \\
\hline Corr & ockets Out of the & Podium & & 5 & 7 & 2 & & \\
\hline & Average Rank & & & 2.18 & 2.43 & 1.45 & & \\
\hline & Precision & & & 0.5 & 0.45 & 0.75 & & \\
\hline & Accuracy & & & 0.97 & 0.97 & 0.99 & & \\
\hline & MCC & & & 0.48 & 0.43 & 0.74 & & \\
\hline
\end{tabular}


The main protease (3-chymotrypsin like protein, 3CL-PRO) is a key enzyme involved in viral replication and transcription. Hence, this is a very attractive antiviral target and several resolved structures have been already released. Some resolved structures are in complex with inhibitors thus allowing a precise characterization of its binding cavity. Similarly, screening studies proposed some potential 3CL-PRO inhibitors including both covalent and non-covalent ligands [15]. Here, a total of 14 resolved SARS-CoV-2 3CL-PRO structures were analyzed (5R7Y, 5R7Z, 5R80, 5R81, 5R82, 5R83, 5R84, 6LU7, 6M2N, 6M03, 6Y2E [16], 6Y2F, 6Y2G, 6Y84).

The nucleocapsid protein (N-protein) of Coronaviruses is a structural protein, which packs the RNA genome forming a helical nucleocapsid structure or ribonucleoprotein (RNP) complex [17]. Two X-ray structures of SARS-CoV-2 are already available (PDB Id: 6M3M and 6VYO) but in their apo form. However, five N-protein resolved structures from Human coronavirus OC43 (HCoV-OC43) co-crystallized with different ligands within the RNA-binding site (i.e., C5P, 5GP, U5P, AMP, P34 (inhibitor) with PDB Id: 4LMC, 4LM9, 4LM7, 4LI4, 4KXJ, respectively [37]) are available. The binding site is extremely conserved, leading to easy identification of the corresponding pocket in the SARS-CoV-2 protein.

The ADP ribose phosphatase nsp3 of SARS-CoV-2 was crystallized early this year (PDB Id: 6W02) in complex with the substrate ADP ribose, thus allowing a precise characterization of its catalytic cavity. Nsp3 is believed to play key roles in virus replication, which go beyond the simple phosphatase activity, although many of its functions remain to be investigated [38].

Nsp6 is a membrane-spanning protein involved in the compartmentalized viral RNA synthesis [39]. Until now, no crystal structure was resolved but a theoretical model can be generated by de novo modelling. Even though specific information concerning the nsp6 binding sites are not available, a recent analysis of known SARS-CoV-2 mutants highlighted the key role of a cluster composed of aromatic residues and located within the extracellular loop between the first two transmembrane regions in reasonably determining activity and stability of the proteins, since it might be involved in the interaction with the membrane of the endoplasmic reticulum [18]. Moreover, a potent nsp6 inhibitor (K22) was reported for several coronaviruses and its antiviral activity was ascribed to its capacity to interfere with the interaction between nsp6 and the membrane structure [40].

The nsp9 replicase protein of SARS-CoV-2 was recently resolved (PDB Id: 6W4B). This enzyme is believed to bind RNA-single strand in the viral replication complex [19,41]. So far, no proper binding pockets have been identified on this protein. However, the crystal structure of nsp9 SARS-CoV (PDB Id: 1QZ8 [20]) suggests that molecules could bind close to the RNA binding site. In detail, the putative site for inhibitors can be derived by the observation that nsp9 is structurally homologous to the subdomains of serine proteases, in particular to the second domain of coronavirus 3CLpros (PDB Id: 1P9U, in complex with the protease inhibitor PRD_000457) and to the first domain of human rhinovirus 3CLpros (PDB Id: 1CQQ, co-crystallized with RUPINTRIVIR a peptidomimetic inhibitor) [42].

Nsp12 is an RNA-dependent RNA polymerase (RdRp) and is the main enzyme responsible for the RNA replication of the virus, making it an appealing target for the pharmacological treatment of the SARS-CoV-2 infection. Two structures of SARS-CoV-2 nsp12 in complex with its cofactors nsp7 and nsp 8 were recently resolved (PDB Id: 6M71 and 7BV2). As depicted by Figure 1, one of these structures (i.e., 7BV2) is co-crystallized with the inhibitor remdesivir, allowing the precise identification of the orthosteric site (Figure 1A). Furthermore, a search for allosteric pockets was also performed since SARS-CoV nsp12 shows structural similarity with the RNA-dependent RNA polymerase of Hepatitis C virus (HCV), called NS5B [43], as both enzymes share the well-known "hand" shape and NS5B is regulated by allosteric modulation [44-46]. In detail, three allosteric sites were identified on NS5B: two on the "thumb" (Figures 1B and 1C), and one on the "palm" (Figure 1D). These sites were co-crystallized with three different inhibitors (PDB Id: 2BRL, 2HAI, and 3HHK, Table 1) [21-23,47]. All these resolved structures belong to the HCV genotype 1 for which allosteric modulation was best established [48]. Thus, these crystal structures were utilized as a reference for identifying the putative corresponding allosteric sites on the homology model of SARS-CoV-2 nsp12. 


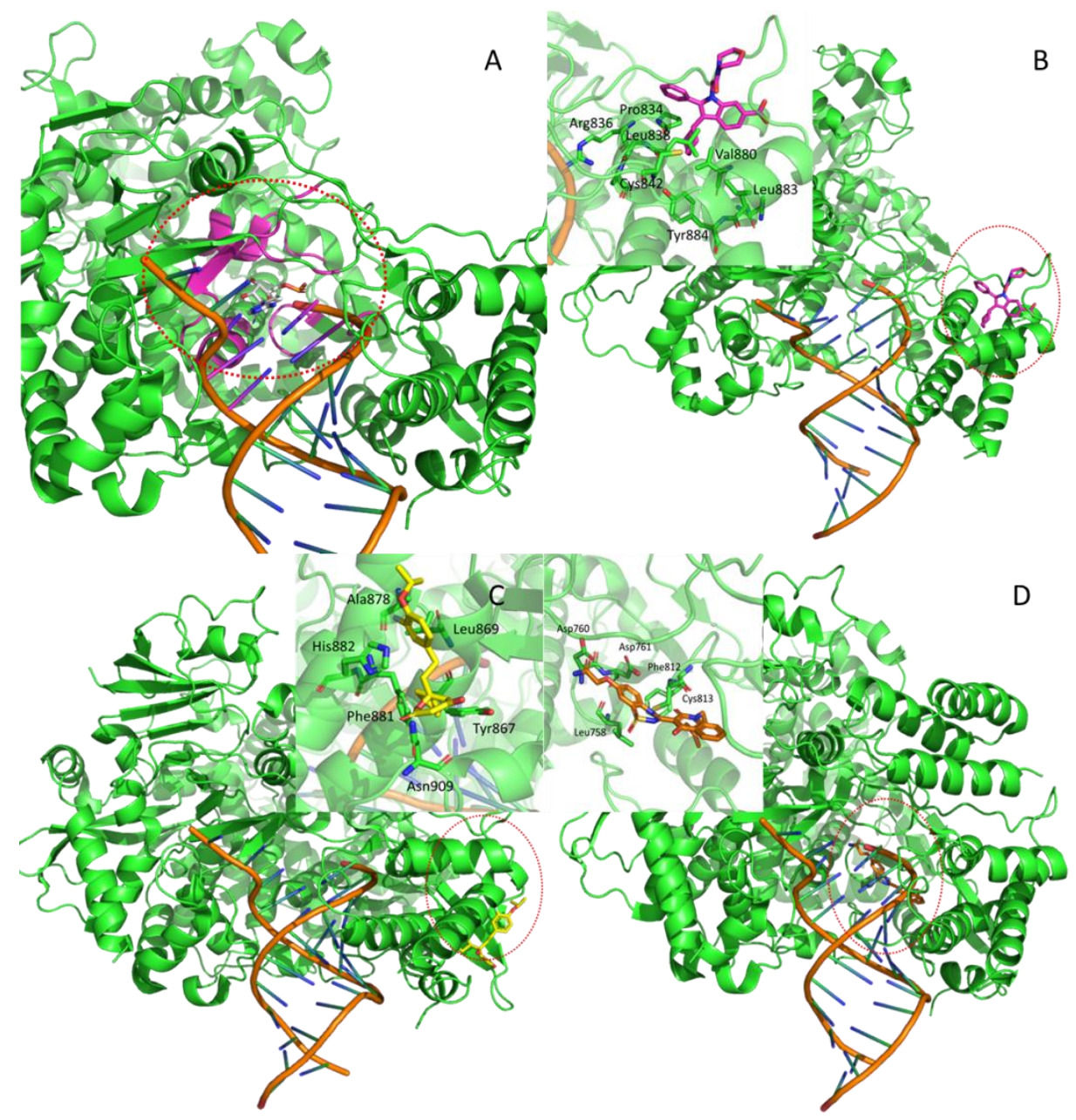

Figure 1. Identified binding sites within the resolved nsp12 structure (PDB Id: 7BV2): the orthosteric cavity in complex with remdesevir (A) plus three potential allosteric sites, among which two are located on the "thumb" as defined in their putative complexes with POO (B) and PFI (C) plus one site on the palm in the predicted complex with $77 Z$ (D).

The helicase nsp13 catalyzes the unwinding of oligonucleotides duplex into single strands. Given its vital role in virus replication, this has been pointed out as a promising pharmacological target [24]. For this reason, a homology model was built using the crystal structure of MERS-CoV nsp13 (PDB Id: 5 wwp [25]) as the template and we looked for possible binding sites. The orthosteric site was retrieved from the resolved structure of the helicase Upf1 from Saccharomyces Cerevisiae (PDB Id: 2XZL [26]) which belongs to the Super Family 1 (SF1) of helicases, similarly to SARS-CoV nsp13. Upf1 is in complex with RNA and ADP: AlF4-, which mimics the transition state of the ATP hydrolysis reaction. The orthosteric site is highly conserved and a good agreement between the binding site residues of the crystal structure and the SARS-CoV-2 homology model was found. A putative allosteric site for nsp13 was also derived from the NS3 helicase of HCV (PDB Id: 4B75 [49]). The inhibitor binds at the interface between NS3 and NS4, preventing the interaction between the two proteins. Given the similarity between the structures and the involved residues, a similar allosteric site was also supposed for nsp13, which could be responsible for modulating the interaction with nsp12.

Nsp14 is a (guanine-N7) methyltransferase (N7-MTase) for mRNA capping. Currently, no resolved structure for SARS-CoV-2 nsp14 is available, but the protein can be modeled by homology techniques as the heterodimer nsp10-nsp14, using the available crystal structures of the SARS-CoV nsp10-nsp14 heterodimer (PDB Id: 5C8S [27]) as the template. Luckily, the template was resolved in complex with the functional ligands involved in the catalytic reactions (namely the GpppA substrate and the 
demethylated SAH cofactor) thus allowing a precise characterization of the catalytic pocket within the modeled SARS-CoV-2 nsp14 structure.

Nsp15 is a uridylate-specific endoribonuclease, the structure of which was recently resolved in complex with citrate (PDB Id: 6W01 [50]). The orthosteric cavity was derived by comparison with the corresponding resolved structures from SARS-CoV (PDB Id: 2H85 [51]). Even though both structures were in their apo form, the orthosteric cavity was identified based on sequence alignment and mutational analyses within the C-terminal domain. As depicted in Figure 2, the so identified cavity was finally verified by preliminary docking simulations with the uridine 3 '-phosphate ligand, which produced a pose in encouraging agreement with that proposed for SARS-Cov and Middle East respiratory syndrome coronavirus (MERS-Cov) nsp1. [52,53].

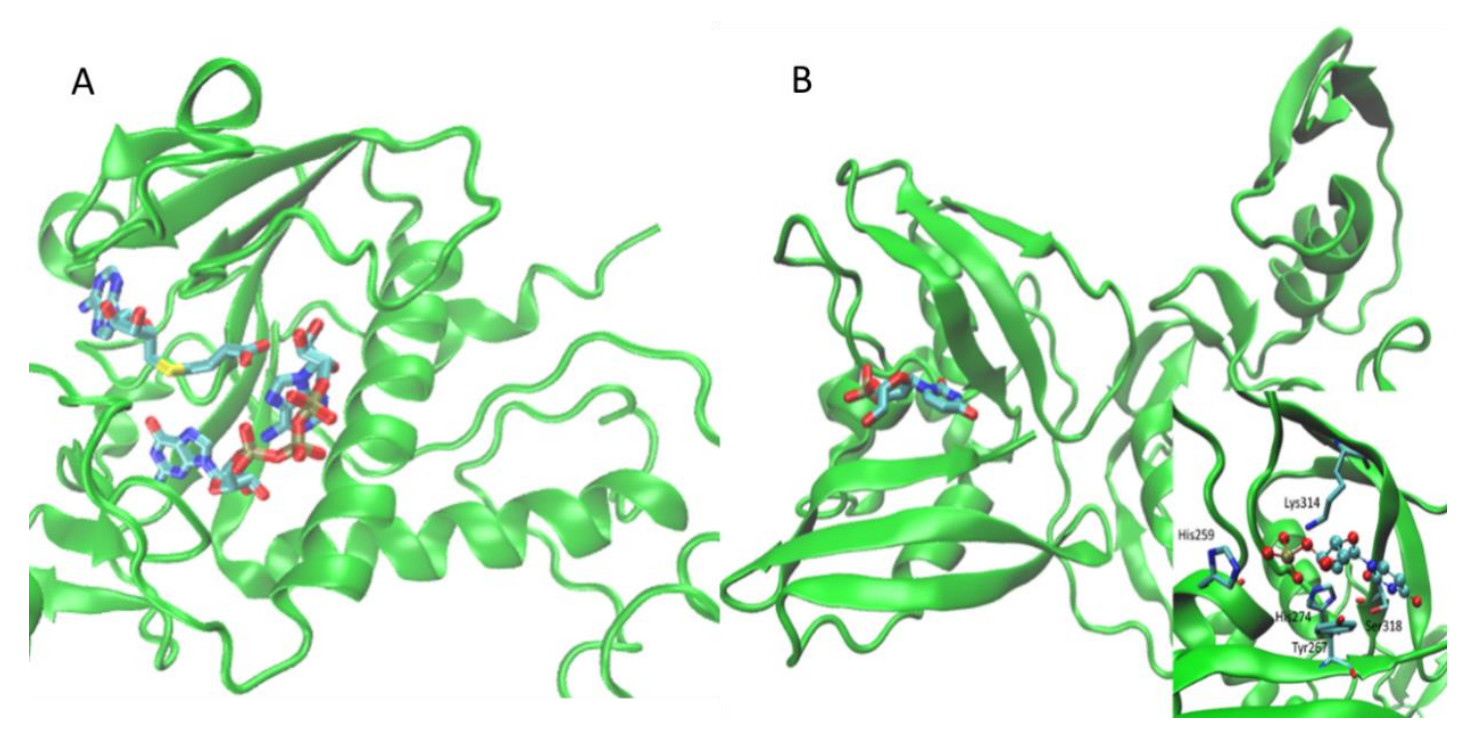

Figure 2. Identified orthosteric cavities within the nsp14 in complex with its ligands, GpppA, and SAH (A), as well as within the C-terminal domain of nsp15 in the putative complex with its substrate uridine $3^{\prime}$-phosphate (B). In the inlet of 2B, the key contacts stabilizing the complex.

Nsp16 is a 2' O-methyltransferase [54] and two resolved structures are available in complex (PDB Id: 6W4H and 6WKS) with its cofactor nsp10, which is essential for the activity. The first structure is co-crystallized with SAM, while the second one includes both SAM and the P1-7-methylguanosine-P3-adenosine- $5^{\prime}, 5^{\prime}$-triphosphate (GTA) substrate, thus allowing precise identification of the overall catalytic pocket.

The papain-like protease of SARS-CoV-2 (PL-Pro) [28] was recently resolved (PDB Id: 6W9C) in its apo form. A putative binding cavity was derived by the comparison with the corresponding structure from SARS-CoV co-crystallized with a potent inhibitor (PDB Id: 3E9S in complex with TTT).

A last SARS-CoV-2 protein that has attracted great interest in its role in the viral entry is the Spike protein, the receptor-binding domain (RBD) of which is recognized by the human receptor angiotensin-converting enzyme 2 (ACE2) [29]. Hence, different resolved proteins of the sole trimeric SARS-CoV-2 spike protein (PDB Id: 6LVN, 6LXT [30], 6VSB [31], 6VXX [32], 6VYB [33]) as well as of its RBD in complex with ACE2 (PDB Id: 6LZG [34], 6M0J [35], 6M17 [36], 6VW1 [55]) were recently reported. Rather than druggable pockets, these complexes allow a precise characterization of the protein-protein interactions by revealing the key regions involved in spike-ACE2 recognition. In the following docking simulations, the pocket analysis was performed by using mefloquine as the probe ligand since it was recently reported to be able to inhibit the spike-ACE2 interaction [56].

Finally and to the best of our knowledge, no binding sites can be identified by analyzing homologous proteins for the non-structural proteins nsp2, nsp4, nsp7-nsp8, and nsp10. Similarly, 
the membrane protein (M-protein) and the Open Reading Frame (ORF) proteins (ORF3a, 6, 7a, 7b, $8,10)$ are structural proteins for which no druggable site can be found [57].

Such a preliminary analysis allowed the identification of 16 binding pockets within 12 different SARS-CoV-2 proteins: in detail, the orthosteric pocket was identified in all proteins, apart from nsp6 and the Spike protein where the hot spots for the ACE2 interaction were yet detected, an allosteric site was also recognized within nsp6 and nsp13, while at least three allosteric pockets were identified for nsp12. In the following part of the study, the identified binding pockets will be used as a test set to validate the performances of Pockets 2.0 by evaluating its capacity to recognize them as the best pocket when ranked by combining pocket and docking searches compared to the two methods taken separately (as reported in Table 2). For simplicity, the identified binding pockets will be named hereinafter as the "correct pockets".

\subsection{Pockets 2.0 Performances}

As mentioned above, the performances of combining pocket searches and docking calculations were assessed by evaluating the Pockets 2.0 capacity to recognize the 16 previously identified correct pockets as derived from literature search and structural comparisons. Since in several cases, more than one structure was analyzed for each protein (for example, 14 resolved structures were analyzed for 3CL-PRO) and/or more than one ligand was considered for each pocket, this benchmarking study involved 40 pocket searches overall.

Table 2 shows all the investigated proteins with the corresponding detected pockets and the considered probe ligands. Even though the considered 3CL-PRO structures were resolved in complex with different ligands, the pocket searches were repeated by always using the non-covalent inhibitor included in the 6MN2 structure (i.e., 5,6,7-trihydroxy-2-phenyl-4H-chromen-4-one, 3WL) to avoid covalent ligands and to obtain comparable results.

In order to evaluate the correctness of the predicted best pocket, an unbiased approach, which is amenable when analyzing co-crystallized proteins, might be based on rmsd analysis or on volume overlapping between the bound ligand and the pocket shape (as generated by FPocket) or the docked probe molecule (as computed by PLANTS). Unfortunately, the reported analysis involves both theoretical models and resolved proteins with no bound ligands. In these cases, the arrangement of the orthosteric and allosteric binding sites was argued by structural comparison with homologous proteins (as described above) and there are no reference bound ligands for which rmsd or volume overlapping can be evaluated. Hence, the identification of the correct pockets is here based on the identification of some key residues lining the binding site and the detected pockets are evaluated by considering their distance to these key residues. Clearly, the correct pocket is the closest one to the key residues and the binding site is defined as correctly recognized if the closest pocket is ranked as the first pocket (by FPocket, by PLANTS and by consensus score). For example, the performances for 3CL-PRO were evaluated by considering the ranking of the detected pocket closest to the catalytic Cys145 residue.

As explained under Methods, docking simulations were systematically performed within all found pockets using PLANTS. In order to evaluate the Pockets2.0 capacity to recognize the correct pockets, Table 2 also compiles their ranking as based on the FPocket scores, on the docking scores and on the consensus of both scores. For each pocket search, Table 2 reports the volume and the ChemPLP scores as computed by PLANTS for the corresponding correct pockets.

The analysis of the so obtained performances allows for some meaningful considerations. Above all, the combination of FPocket searches and docking calculations leads to a marked improvement in the number of correctly identified pockets since the consensus score recognizes 30 correct pockets out of 40 , with an overall satisfactory precision equal to 0.75 . Even though the pocket searches involving theoretical models are markedly lower compared to those on the resolved proteins (7 vs. 33), the obtained results do not seem to be influenced by the source of the protein structure since the correct cavity was ranked as best pocket within theoretical models in four cases out of seven. 
In detail, FPocket alone was able to recognize one half of the correct pockets ( 20 out of 40 , precision $=0.50$ ), a performance which is in line with that reported by the above mentioned benchmarking study for FPocket when used without repetitions [10]. The performances of docking scores alone are slightly worse than those reached by FPocket $(18$ out of 40 , precision $=0.45$ ) even though it should be noted that docking simulations are not blindly performed on all the protein surfaces but they are focused on the pockets previously detected by FPocket and thus the docking performances unavoidably benefit (at some extent) of the encouraging results offered by FPocket. That being said, one may observe that in 24 cases (out of 40) the rankings of the correct pocket as computed by FPocket and docking simulations do not match and this underlines that docking simulations, while benefitting from the good FPocket performances, encode for additional information that is not simply ascribable to the pocket's local features.

Interestingly, the consensus score clearly reduces the number of cavities that are incorrectly ranked as second or third cavity compared to the Fpocket or docking scores alone. This indicates that the combination of the two scores allows the pockets that were incorrectly ranked by the two search methods alone to be promoted as the best pocket. In detail, the analysis of the 30 pockets correctly identified by the consensus score reveals that only in 11 cases (out of 11), the correct pockets were ranked as the best cavity by both methods, in 13 cases (out of 16), the correct pockets were ranked as non-best solutions by one method, and in 6 cases (out of 13), the correct pockets were ranked as non-best solutions by both methods. These results reveal that in 19 cases (out of 29), the combination of both methods played a crucial role in identifying the correct pocket, thus emphasizing the remarkable potential of the here proposed combined approach. Intriguingly, the above reported results also allow for another interesting interpretation since they reveal that the correct cavity is successfully recognized in $100 \%$ of the cases when both methods ranked it as the best solution. The probability of recognizing the correct cavity decreases to $81 \%$ if at least one method ranked it as the best pocket, dropping to $46 \%$ if both methods are unable to recognize it as the best solution. These results suggest that the combination of pocket and docking searches affords a mutual validation, which increases the reliability of the predicted pockets.

The validation of the here proposed method can be also assessed by considering that the performed pocket searches involved a total of 1364 cavities, which can be subdivided into 40 correct pockets and 1324 incorrect pockets. This means analyzing confusion matrices including a) 20, 18 and 30 true positives; b) 20, 22 and 10 false positives and false negatives and c) 1304, 1302 and 1314 true negatives for Fpocket, PLANTS and consensus rankings, respectively. While considering such an unbalanced dataset, the increase in the MCC value as obtained by combining pocket and docking search (from 0.48 to 0.74 ) affords a further confirmation of the potential of the here proposed approach.

A detailed analysis of the investigated proteins reveals that the pocket search for the 14 resolved 3CL-PRO structures is substantially driven by FPocket, which indeed recognizes the correct pocket in 11 cases. These notable FPocket performances can be here explained by considering that its score, while also including parameters related to the local features of the pockets, tends to favor the large pockets. While considering a certain degree of heterogeneity among the reported pocket volumes, which is explainable by considering that even small changes in the arrangement of the lining side chains can induce a different pocket fragmentation by FPocket, the 3CL-PRO catalytic cavity is by far the largest pocket and thus is almost always correctly recognized by FPocket. When discarding the 3CL-PRO structures, the results markedly change since FPocket is able to recognize the correct pocket only in 9 cases out of 26 , and the pocket search appears to largely benefit from docking simulations as evidenced by the fact that consensus score correctly recognizes 18 pockets out of 26 . These last results emphasize how the combination of pocket and docking searches could be particularly effective when exploring complex proteins endowed with narrow binding cavities, and indeed it appears truly productive when looking for allosteric binding sites, as seen for nsp6 and nsp12.

The analysis of the pockets for nsp12 and the Spike protein deserves a separate description. With regard to the nsp12 allosteric cavities, the two cavities on the thumb region can be identified with 
difficulty due to the folding of some loops, which partly occupy the cavities, thus leading to their unsatisfactory fragmentation. Hence, the cavity n. 2 was selected since it is large enough to encompass both allosteric sites while not matching either one specifically. Again, the allosteric cavity on the palm region is merged to the orthosteric site, thus generating a unique very large binding site (pocket $n .1$ ), which can suggest the design of bivalent ligands able to interact with both subpockets.

Concerning the Spike protein, all simulations involved the resolved complexes of Spike-ACE2 even though the pockets detected on the ACE2 surface were discarded from the analyses. Though to test the Pockets 2.0 performances, the analysis of the largest Spike-ACE2 complex (PDB Id: 6M17), a hexamer that also includes two chains of the sodium-dependent neutral amino acid transporter B(0)AT1, was also repeated by considering all 275 detected pockets. Gratifyingly, FPocket ranks the correct pocket in the eleventh position while docking simulations proved successful to recognize the correct pocket even in such a challenging situation, and the pocket was ranked as the second one by consensus score, thus further confirming the key role of docking simulations to identify the druggable cavities.

With regard to the badly predicted pockets, there are only two cases in which the correct pocket is ranked off the podium, namely the allosteric site of nsp13 and the orthosteric cavity of the nsp10-14 for the SAH ligand. The unsatisfactory prediction of the nsp13 allosteric pocket can be justified by considering that this binding site should be located at the interface between nsp13 and nsp 12 (see above), and thus cannot be properly mapped by considering only nsp13. Again, the wrong prediction for the nsp10-14 heteromer is due to unsuitable docking results, which can be rationalized by considering that $\mathrm{SAH}$ is in fact the reaction product and indeed the performances significantly enhance when considering SAM, which is the true cofactor.

\section{Materials and Methods}

\subsection{Protein Structures}

Available experimental structures were downloaded from the PDB (the corresponding PDB Ids are reported in Table 2). The two analyzed homology models for nsp13 and the nsp10-nsp14 heteromer were retrieved by the dedicated SWISS-MODEL page which comprises models for the full SARS-CoV-2 proteome (https://swissmodel.expasy.org/repository/species/2697049). Homology modelling (HM) was performed by SWISS-MODEL [58]. SWISS-MODEL identifies suitable homologues to be used as modelling templates with BLAST [59] and HHblits [60] in the SWISS-MODEL Template Library. Model building using the identified templates and their associated target-template sequence alignments was delegated to the ProMod3 modelling engine (Swiss Institute of Bioinformatics and Biozentrum, Basel, Basel), which performs the following steps: (1) extraction of structural information from the template; (2) loop modelling using an internal loop database or Monte Carlo sampling; (3) side chain modeling using an internal backbone-dependent rotamer library and optimization with the graph-based TreePack algorithm [61] minimizing the SCWRL4 energy function [62]; (4) energy minimization using OpenMM [63] with the CHARMM force field [64]. The global and per-residue model quality of the final models was assessed by the QMEAN scoring function [65] and QMEANDisCo, respectively [66]. The homology models have been deposited in the ModelArchive database with the unique stable accession codes (DOI) https://modelarchive.org/doi/10.5452/ma-epkbe for nsp13 and https://modelarchive.org/doi/10.5452/ma-3rg44 for the nsp10-14 heteromer. De novo models (DN) for nsp6 were obtained from the Feig group (https://github.com/feiglab/sars-cov-2-proteins) [67]. Specifically, the FeigLab and AlphaFold-refined models of nsp6 were used.

\subsection{Preliminary Simulations}

Be they resolved or modelled, all simulated proteins were prepared by adding (when necessary) the hydrogen atoms to remain compatible at physiological $\mathrm{pH}$ and by removing (when present) water solvents, crystallization additives, and bound ligands. The protein structures were then minimized 
by using Namd2 (NIH Center for Macromolecualr Modeling \& Bioinformatics, Urbana-Champaign, Illinois, USA) [68] and by keeping the backbone atoms fixed to preserve the resolved or predicted folding. In detail, the minimizations were carried out by using the conjugate gradient algorithm until RMS $=0.01 \mathrm{kcal} \mathrm{mol}^{-1} \AA^{-1}$ (maximum number of steps = 10000) with the CHARMM force field and the Gasteiger's atomic charges. All tested probe ligands were optimized by PM7 semi-empirical calculations [69]. When necessary to further assess the pocket reliability (as in the case of nsp15), preliminary docking simulations were performed using PLANTS (Theoretische Chemische Dynamik, Konstanz, Germany) [13] and focusing the search on a $10 \AA$ radius sphere around the identified key residues. For each simulation, 10 poses were generated and ranked by ChemPLP with speed equal to 1 .

\subsection{The Pockets 2.0 Approach}

Starting from release 2.4, the VEGA ZZ suite of programs (Drug Design Laboratory, Milan, Italy) comprises a graphical interface to FPocket (named Pocket plug-in) [70]. FPocket (Ressource Parisienne en BioInformatique Structurale, Paris, France) is a well known software to detect protein cavities, which is based on an extremely optimized algorithm for Voronoi tessellation, the performances of which allow even complex macromolecules to be rapidly analyzed [4]. Here a new version of the plug-in for FPocket (named Pockets 2.0) is described. For a better exploration of the protein cavities, this combines the already implemented cavity mapping as performed by Fpocket with docking calculations with probe molecule(s) using AutoDock/Vina or PLANTS docking programs. To optimize the ranking of the explored cavities, Pockets 2.0 can utilize both Fpocket and docking scores by calculating customizable consensus scores.

Figure 3 shows the Pockets 2.0 workflow for the identification and prioritization of the potential binding sites for a given protein. The plug-in accepts as primary input the 3D coordinates of the target protein, which can be in any file format supported by the VEGA ZZ program. The input protein structure is firstly analyzed by FPocket, which finds and ranks the cavities according to its internal score. Along with the scores computed by FPocket, the plug-in adds information concerning the geometric features of each pocket, which will be useful for the following docking calculations.

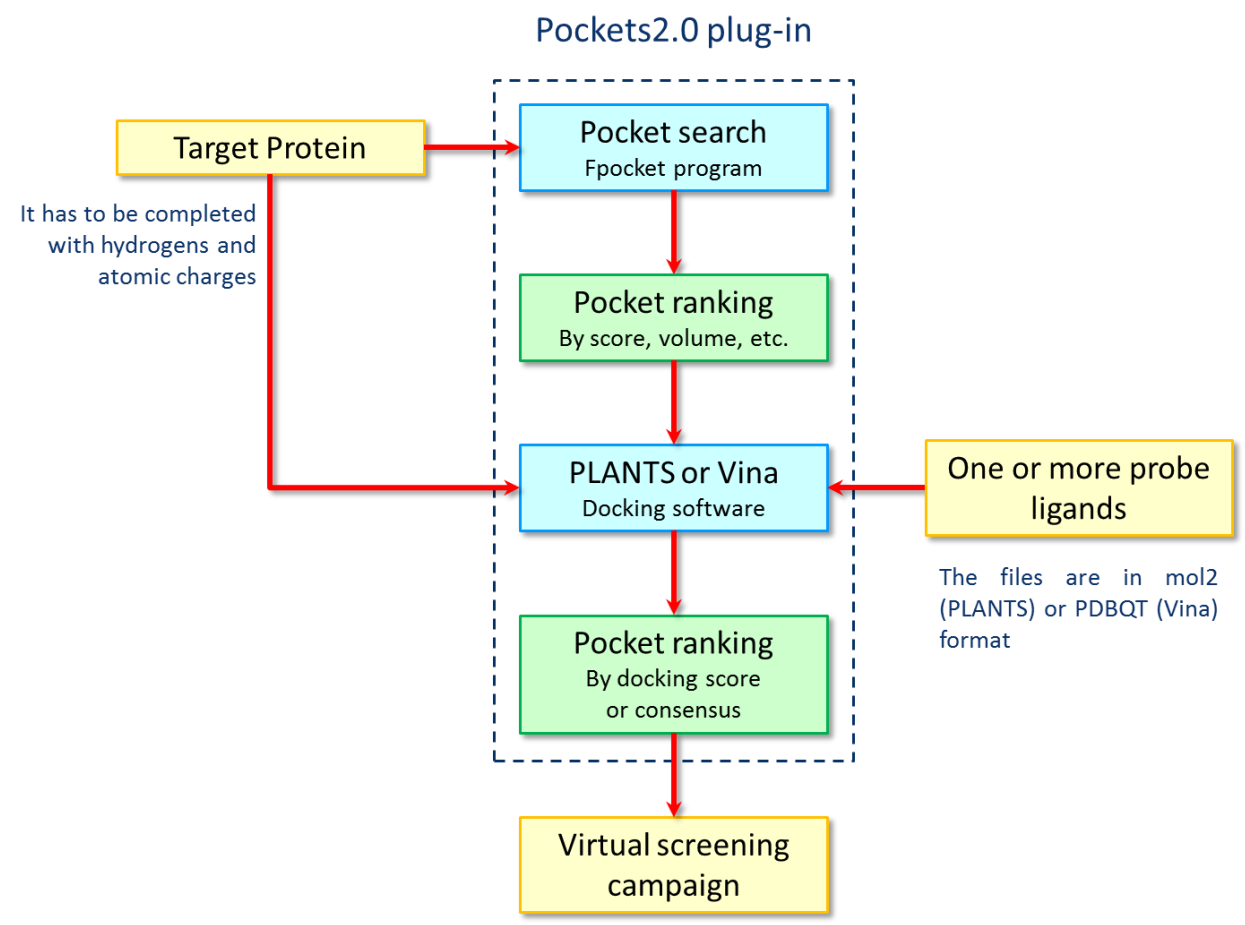

Figure 3. Flowchart describing the main logical steps implemented by Pockets 2.0 to identify and to evaluate druggable protein cavities. 
Once the pockets are calculated and analyzed, they can undergo the docking simulations. To do this, the selected ligand(s) should be suitably prepared depending on the chosen docking program. After setting the docking parameters, the simulations are automatically performed on all selected pockets using all collected probe ligands. Based on all computed scores, user-defined consensus functions can be calculated to afford a combined ranking of all cavities. In the here described analysis of the SARS-CoV-2 proteins, the consensus score is computed by summing the ranks obtained by sorting the overall FPocket scores and the ChemPLP docking scores from best to worst.

Along with the interactive inspection of the found pockets and the corresponding ligand poses within the VEGA ZZ graphical interface, the Pockets 2.0 plug-in generates a set of additional output files regarding the computed poses for each pocket and the corresponding score values.

\subsection{Pocket Search and Analyses}

For the here performed analyses, the pocket search was performed by applying the default settings of FPocket (e.g., minimum and maximum radius of alpha spheres equal to $3 \AA$ and $6 \AA$, respectively) with the only exception of the minimum number of spheres to define a pocket that was set equal to 30 (instead of 35) for a more exhaustive analysis even of the small cavities. For each protein, all found cavities underwent docking simulations using PLANTS. In detail, the search was focused within the corresponding spheres as derived from FPocket analysis by increasing their radius of $3 \AA$ to completely encompass the entire binding cavity. For each simulated ligand and each explored cavity, one pose was generated by using the PLANTS_ChemPLP scoring function with speed equal to 1 . In all the analyses, the consensus function of each pocket was computed by combining the overall FPocket score with the ChemPLP score. When more than one ligand was used as a probe for a pocket, the consensus score involves the average of the corresponding ChemPLP scores. Since almost all the analyzed SARS-CoV-2 proteins are enzymes with various catalytic activities, the performances of the here presented combined approach was preliminarily assessed, also considering a set of resolved GPCRs, the evaluation of which was reported in the Supporting Information. As summarized in Table S1, the obtained results also afford an encouraging validation with this class of proteins since the combination of pocket and docking search was able to identify the correct pocket with an overall precision equal to 0.91 , even greater than that obtained with the SARS-CoV-2 targets.

\section{Conclusions}

The study had two primary objectives: characterizing the druggable binding sites within the therapeutically relevant SARS-CoV-2 proteins as well as presenting and validating a novel strategy to search and prioritize the protein pockets by using the identified SARS-CoV-2 sites as a test set. Concerning the first objective, an extensive literature search combined with the comparison with homologous proteins allowed precise identification of 16 druggable pockets within 12 different SARS-CoV-2 proteins, including four allosteric sites. In this context, nsp12 represents a very interesting target since its homology with the corresponding HCV enzymes allowed the identification of at least three allosteric pockets, which can play key roles in determining the nsp12 activity as well as its interactions with the cofactor proteins.

Concerning the second objective, the study reports the Pockets 2.0 plug-in as implemented in the VEGA ZZ suite of programs, which automatically combines the pocket search, as performed by FPocket, with docking simulations by using representative probe ligands and PLANTS or AutoDock/Vina as docking engines. The combination of the FPocket and docking scores by calculating customizable consensus scores leads to a significant increase in the correctly identified binding sites compared to the FPocket and docking scores alone, and this enhancement appears to be truly relevant when considering the MCC values which, while considering the dataset unbalancing, show an increase of $35 \%$ when combining pocket and docking searches.

Again, an ancillary analysis involving an extended set of aminergic resolved GPCRs (see Supporting Information) revealed that the here proposed approach provides even better performances with this 
class of therapeutically relevant proteins. Clearly, these encouraging results should be corroborated by more extended analysis, including different proteins of increasing complexity, to verify the general applicability of this strategy. Notably and since docking simulations can involve more than one ligand, Pockets 2.0 can be also used as a powerful tool to perform focused blind docking simulations by which even extended ligand datasets can be simultaneously docked into different potentially relevant binding pockets.

All prepared protein and ligand structures, as well as all files generated by Pockets 2.0 searches, are available at http://www.exscalate4cov.network. The repository will be periodically updated by including the pocket mapping for the new available target proteins. The homology models have been deposited in the ModelArchive database with the unique stable accession codes (DOI) https: //modelarchive.org/doi/10.5452/ma-epkbe for nsp13 and https://modelarchive.org/doi/10.5452/ma-3rg44 for the nsp10-14 heteromer. The Pockets 2.0 plug-in is freely available within the VEGA ZZ suite of programs at http://www.vegazz.net.

Supplementary Materials: The following are available online at http://www.mdpi.com/1422-0067/21/14/5152/s1, Table S1: Results of the pocket analysis as performed by Pockets 2.0 on the collected GPCR targets. The Pockets 2.0 performances were evaluated by considering its capacity to identify the orthosteric and allosteric sites within the selected GPCR complexes.

Author Contributions: A.P., G.V., A.R.B. designed the study, S.G. performed the literature search, G.S., G.T., A.M.W. and T.S. generated theoretical models, A.P. developed the Pockets 2.0 plug-in, C.M., C.T., A.P. performed simulations to validate the method, G.V. wrote the manuscript, A.R.B. was responsible for the project administration and funding acquisition. All authors have read and agreed to the published version of the manuscript.

Funding: This research was conducted under the project "EXaSCale smArt pLatform Against paThogEns for Corona Virus-Exscalate4CoV" founded by the EU's H2020-SC1-PHE-CORONAVIRUS-2020 call, grant N. 101003551.

Acknowledgments: We thank sciCORE at the University of Basel for providing computational resources and system administration support.

Conflicts of Interest: The authors declare no conflict of interest.

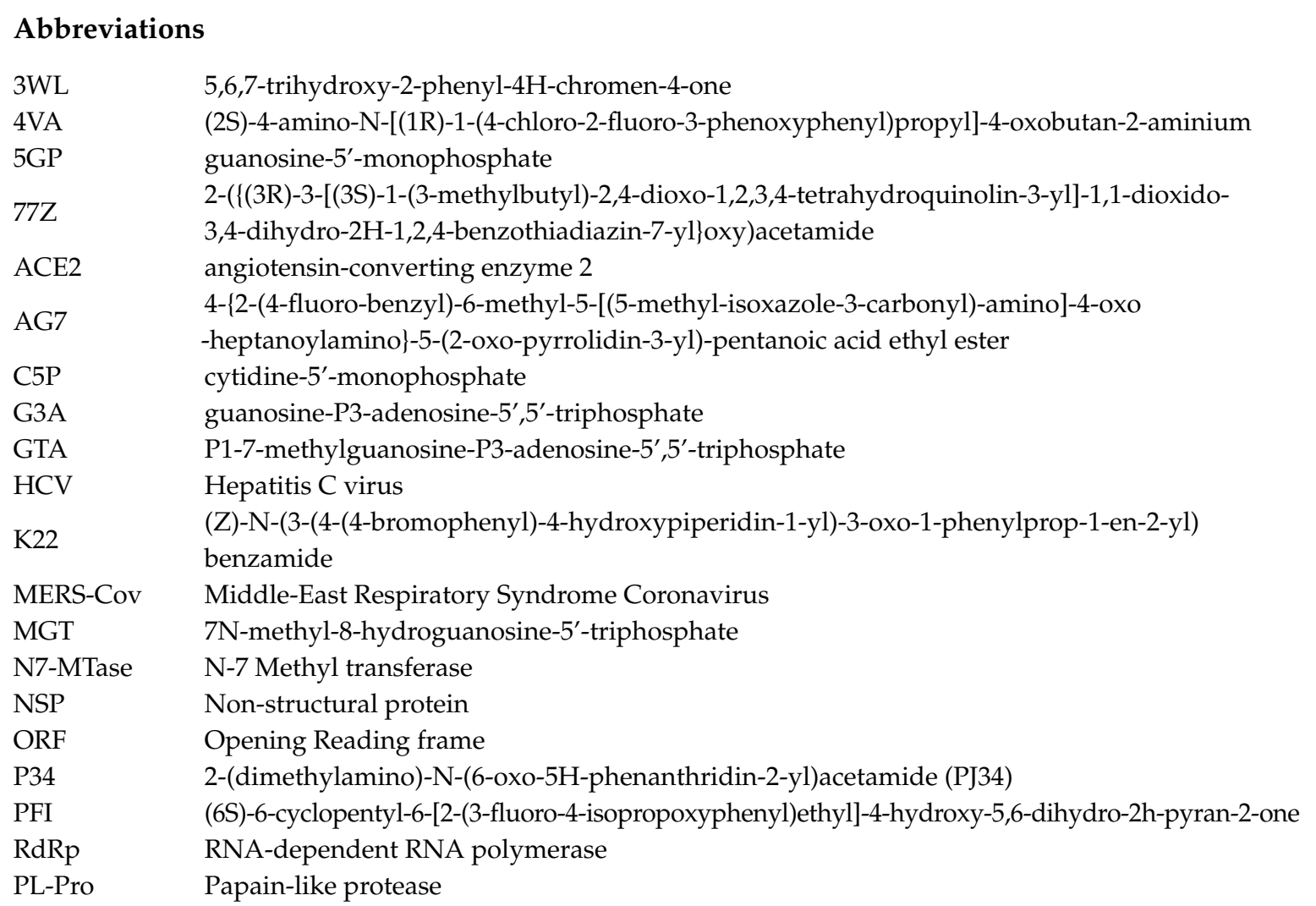




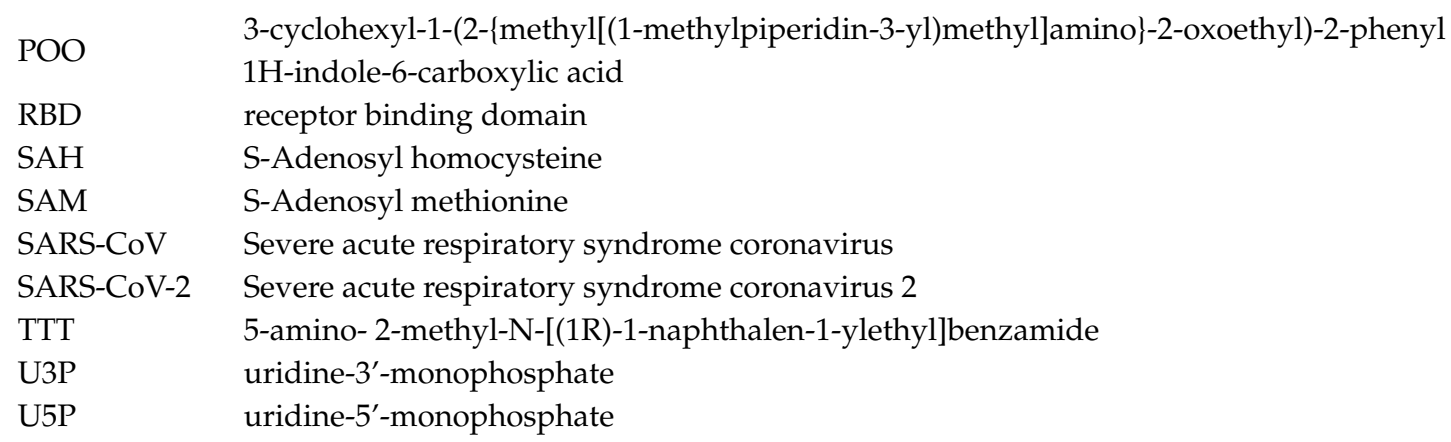

\section{References}

1. Macari, G.; Toti, D.; Polticelli, F. Computational methods and tools for binding site recognition between proteins and small molecules: From classical geometrical approaches to modern machine learning strategies. J. Comput. Mol. Des. 2019, 33, 887-903. [CrossRef] [PubMed]

2. Stank, A.; Kokh, D.B.; Fuller, J.; Wade, R.C. Protein Binding Pocket Dynamics. Accounts Chem. Res. 2016, 49, 809-815. [CrossRef]

3. Pérot, S.; Sperandio, O.; Miteva, M.A.; Camproux, A.-C.; Villoutreix, B.O. Druggable pockets and binding site centric chemical space: A paradigm shift in drug discovery. Drug Discov. Today 2010, 15, 656-667. [CrossRef] [PubMed]

4. Le Guilloux, V.; Schmidtke, P.; Tufféry, P. Fpocket: An open source platform for ligand pocket detection. BMC Bioinform. 2009, 10, 168. [CrossRef] [PubMed]

5. Hendlich, M.; Rippmann, F.; Barnickel, G. LIGSITE: Automatic and efficient detection of potential small molecule-binding sites in proteins. J. Mol. Graph. Model. 1997, 15, 359-363. [CrossRef]

6. Dias, S.; Martins, A.M.; Nguyen, Q.T.; Gomes, A.J. GPU-based detection of protein cavities using Gaussian surfaces. BMC Bioinform. 2017, 18, 493. [CrossRef]

7. Kuntz, I.D.; Blaney, J.M.; Oatley, S.J.; Langridge, R.; Ferrin, T. A geometric approach to macromolecule-ligand interactions. J. Mol. Boil. 1982, 161, 269-288. [CrossRef]

8. Kawabata, T. Detection of multiscale pockets on protein surfaces using mathematical morphology. Proteins Struct. Funct. Bioinform. 2009, 78, 1195-1211. [CrossRef] [PubMed]

9. Kellenberger, E.; Müller, P.; Schalon, C.; Bret, G.; Foata, N.; Rognan, D. sc-PDB: An Annotated Database of Druggable Binding Sites from the Protein Data Bank. J. Chem. Inf. Model. 2006, 46, 717-727. [CrossRef] [PubMed]

10. Dias, S.; Simões, T.; Fernandes, F.; Martins, A.M.; Ferreira, A.; Jorge, J.; Gomes, A.J.P. CavBench: A benchmark for protein cavity detection methods. PLoS ONE 2019, 14, e0223596. [CrossRef] [PubMed]

11. Hussein, H.A.; Geneix, C.; Petitjean, M.; Borrel, A.; Flatters, D.; Camproux, A. Global vision of druggability issues: Applications and perspectives. Drug Discov. Today 2017, 22, 404-415. [CrossRef] [PubMed]

12. Pedretti, A.; Villa, L.; Vistoli, G. VEGA: A versatile program to convert, handle and visualize molecular structure on Windows-based PCs. J. Mol. Graph. Model. 2002, 21, 47-49. [CrossRef]

13. Korb, O.; Stützle, T.; Exner, T.E. Empirical Scoring Functions for Advanced Protein-Ligand Docking with PLANTS. J. Chem. Inf. Model. 2009, 49, 84-96. [CrossRef] [PubMed]

14. Trott, O.; Olson, A.J. AutoDock Vina: Improving the speed and accuracy of docking with a new scoring function, efficient optimization, and multithreading. J. Comput. Chem. 2009, 31, 455-461. [CrossRef] [PubMed]

15. Jin, Z.; Du, X.; Xu, Y.; Deng, Y.; Liu, M.; Zhao, Y.; Zhang, B.; Li, X.; Zhang, L.; Peng, C.; et al. Structure of $\mathrm{M}$ (pro) from COVID-19 virus and discovery of its inhibitors. Nature 2020. [CrossRef] [PubMed]

16. Zhang, L.; Lin, D.; Sun, X.; Curth, U.; Drosten, C.; Sauerhering, L.; Becker, S.; Rox, K.; Hilgenfeld, R. Crystal structure of SARS-CoV-2 main protease provides a basis for design of improved $\alpha$-ketoamide inhibitors. Science 2020, 368, eabb3405. [CrossRef] [PubMed]

17. Chang, C.-K.; Hou, M.-H.; Chang, C.-F.; Hsiao, C.-D.; Huang, T.-H. The SARS coronavirus nucleocapsid protein-Forms and functions. Antivir. Res. 2014, 103, 39-50. [CrossRef] [PubMed] 
18. Benvenuto, D.; Angeletti, S.; Giovanetti, M.; Bianchi, M.; Pascarella, S.; Cauda, R.; Ciccozzi, M.; Cassone, A. Evolutionary Analysis of SARS-2-CoV: How Mutation of Non-Structural Protein 6 (NSP6) Could Affect Viral Autophagy. SSRN Electron. J. 2020, 0163-4453. [CrossRef]

19. Sutton, G.; Fry, E.; Carter, L.; Sainsbury, S.; Walter, T.; Nettleship, J.; Berrow, N.; Owens, R.; Gilbert, R.; Davidson, A.; et al. The nsp9 Replicase Protein of SARS-Coronavirus, Structure and Functional Insights. Structure 2004, 12, 341-353. [CrossRef]

20. Egloff, M.-P.; Ferron, F.; Campanacci, V.; Longhi, S.; Rancurel, C.; Dutartre, H.; Snijder, E.J.; Gorbalenya, A.E.; Cambillau, C.; Canard, B. The severe acute respiratory syndrome-coronavirus replicative protein nsp9 is a single-stranded RNA-binding subunit unique in the RNA virus world. Proc. Natl. Acad. Sci. USA 2004, 101, 3792-3796. [CrossRef]

21. Davis, B.C.; Brown, J.A.; Thorpe, I.F. Allosteric Inhibitors Have Distinct Effects, but Also Common Modes of Action, in the HCV Polymerase. Biophys. J. 2015, 108, 1785-1795. [CrossRef] [PubMed]

22. Di Marco, S.; Volpari, C.; Tomei, L.; Altamura, S.; Harper, S.; Narjes, F.; Koch, U.; Rowley, M.; De Francesco, R.; Migliaccio, A.R.; et al. Interdomain Communication in Hepatitis C Virus Polymerase Abolished by Small Molecule Inhibitors Bound to a Novel Allosteric Site. J. Boil. Chem. 2005, 280, 29765-29770. [CrossRef] [PubMed]

23. Li, H.; Tatlock, J.; Linton, A.; González, J.; Borchardt, A.; Dragovich, P.; Jewell, T.; Prins, T.; Zhou, R.; Blazel, J.; et al. Identification and structure-based optimization of novel dihydropyrones as potent $\mathrm{HCV}$ RNA polymerase inhibitors. Bioorganic Med. Chem. Lett. 2006, 16, 4834-4838. [CrossRef]

24. Shadrick, W.R.; Ndjomou, J.; Kolli, R.; Mukherjee, S.; Hanson, A.M.; Frick, D.N. Discovering new medicines targeting helicases: Challenges and recent progress. J. Biomol. Screen. 2013, 18, 761-781. [CrossRef] [PubMed]

25. Hao, W.; Wojdyla, J.A.; Zhao, R.; Han, R.; Das, R.; Zlatev, I.; Manoharan, M.; Wang, M.; Cui, S. Crystal structure of Middle East respiratory syndrome coronavirus helicase. PLoS Pathog 2017, 13, e1006474. [CrossRef]

26. Chakrabarti, S.; Jayachandran, U.; Bonneau, F.; Fiorini, F.; Basquin, C.; Domcke, S.; Le Hir, H.; Conti, E. Molecular Mechanisms for the RNA-Dependent ATPase Activity of Upf1 and Its Regulation by Upf2. Mol. Cell 2011, 41, 693-703. [CrossRef]

27. Ma, Y.; Wu, L.; Shaw, N.; Gao, Y.; Wang, J.; Sun, Y.; Lou, Z.; Yan, L.; Zhang, R.; Rao, Z. Structural basis and functional analysis of the SARS coronavirus nsp14-nsp10 complex. Proc. Natl. Acad. Sci. USA 2015, 112, 9436-9441. [CrossRef]

28. Baez-Santos, Y.M.; John, S.S.; Mesecar, A.D. The SARS-coronavirus papain-like protease: Structure, function and inhibition by designed antiviral compounds. Antivir. Res. 2014, 115, 21-38. [CrossRef]

29. Tang, T.; Bidon, M.; Jaimes, J.A.; Whittaker, G.R.; Daniel, S. Coronavirus membrane fusion mechanism offers a potential target for antiviral development. Antivir. Res. 2020, 178, 104792. [CrossRef]

30. Xia, S.; Liu, M.; Wang, C.; Xu, W.; Lan, Q.; Feng, S.; Qi, F.; Bao, L.; Du, L.; Liu, S.; et al. Inhibition of SARS-CoV-2 (previously 2019-nCoV) infection by a highly potent pan-coronavirus fusion inhibitor targeting its spike protein that harbors a high capacity to mediate membrane fusion. Cell Res. 2020, 30, 343-355. [CrossRef]

31. Wrapp, D.; Wang, N.; Corbett, K.; Goldsmith, J.A.; Hsieh, C.-L.; Abiona, O.; Graham, B.S.; McLellan, J.S. Cryo-EM structure of the 2019-nCoV spike in the prefusion conformation. Science 2020, 367, 1260-1263. [CrossRef] [PubMed]

32. Walls, A.C.; Park, Y.-J.; Tortorici, M.A.; Wall, A.; McGuire, A.T.; Veesler, D. Structure, Function, and Antigenicity of the SARS-CoV-2 Spike Glycoprotein. Cell 2020, 181, 281-292. [CrossRef] [PubMed]

33. Wang, Q.; Zhang, Y.; Wu, L.; Niu, S.; Song, C.; Zhang, Z.; Lu, G.; Qiao, C.; Hu, Y.; Yuen, K.-Y.; et al. Structural and Functional Basis of SARS-CoV-2 Entry by Using Human ACE2. Cell 2020, 181, 894-904. [CrossRef]

34. Lan, J.; Ge, J.; Yu, J.; Shan, S.; Zhou, H.; Fan, S.; Zhang, Q.; Shi, X.; Wang, Q.; Zhang, L.; et al. Structure of the SARS-CoV-2 spike receptor-binding domain bound to the ACE2 receptor. Nature 2020, 581, 215-220. [CrossRef]

35. Yan, R.; Zhang, Y.; Li, Y.; Xia, L.; Guo, Y.; Zhou, Q. Structural basis for the recognition of SARS-CoV-2 by full-length human ACE2. Science 2020, 367, 1444-1448. [CrossRef] [PubMed]

36. Shang, J.; Ye, G.; Shi, K.; Wan, Y.; Luo, C.; Aihara, H.; Geng, Q.; Auerbach, A.; Li, F. Structural basis of receptor recognition by SARS-CoV-2. Nature 2020, 581, 221-224. [CrossRef] [PubMed] 
37. Lin, S.-Y.; Liu, C.-L.; Chang, Y.-M.; Zhao, J.; Perlman, S.; Hou, M.-H. Structural Basis for the Identification of the N-Terminal Domain of Coronavirus Nucleocapsid Protein as an Antiviral Target. J. Med. Chem. 2014, 57, 2247-2257. [CrossRef] [PubMed]

38. Lei, J.; Kusov, Y.; Hilgenfeld, R. Nsp3 of coronaviruses: Structures and functions of a large multi-domain protein. Antivir. Res. 2018, 149, 58-74. [CrossRef]

39. Cottam, E.M.; Whelband, M.C.; Wileman, T. Coronavirus NSP6 restricts autophagosome expansion. Autophagy 2014, 10, 1426-1441. [CrossRef]

40. Lundin, A.; Dijkman, R.; Bergström, T.; Kann, N.; Adamiak, B.; Hannoun, C.; Kindler, E.; Jonsdottir, H.R.; Muth, D.; Kint, J.; et al. Targeting Membrane-Bound Viral RNA Synthesis Reveals Potent Inhibition of Diverse Coronaviruses Including the Middle East Respiratory Syndrome Virus. PLoS Pathog 2014, 10, e1004166. [CrossRef]

41. Ponnusamy, R.; Moll, R.; Weimar, T.; Mesters, J.R.; Hilgenfeld, R. Variable Oligomerization Modes in Coronavirus Non-structural Protein 9. J. Mol. Boil. 2008, 383, 1081-1096. [CrossRef] [PubMed]

42. Matthews, D.A.; Dragovich, P.S.; Webber, S.E.; Fuhrman, S.A.; Patick, A.K.; Zalman, L.S.; Hendrickson, T.F.; Love, R.A.; Prins, T.J.; Marakovits, J.T.; et al. Structure-assisted design of mechanism-based irreversible inhibitors of human rhinovirus $3 \mathrm{C}$ protease with potent antiviral activity against multiple rhinovirus serotypes. Proc. Natl. Acad. Sci. USA 1999, 96, 11000-11007. [CrossRef] [PubMed]

43. Deore, R.R.; Chern, J.W. NS5B RNA dependent RNA polymerase inhibitors: The promising approach to treat hepatitis C virus infections. Curr. Med. Chem. 2010, 17, 3806-3826. [CrossRef] [PubMed]

44. Ismail, N.S.M.; Elzahabi, H.S.A.; Sabry, P.; Baselious, F.N.; Abdelmalak, A.S.; Hanna, F. A study of the allosteric inhibition of HCV RNA-dependent RNA polymerase and implementing virtual screening for the selection of promising dual-site inhibitors with low resistance potential. J. Recept. Signal Transduct. 2016, 37, 341-354. [CrossRef] [PubMed]

45. Tomei, L.; Altamura, S.; Bartholomew, L.; Biroccio, A.; Ceccacci, A.; Pacini, L.; Narjes, F.; Gennari, N.; Bisbocci, M.; Incitti, I.; et al. Mechanism of action and antiviral activity of benzimidazole-based allosteric inhibitors of the hepatitis C virus RNA-dependent RNA polymerase. J. Virol. 2003, 77, 13225-13231. [CrossRef] [PubMed]

46. Jácome, R.; Becerra, A.; De León, S.P.; Lazcano, A. Structural Analysis of Monomeric RNA-Dependent Polymerases: Evolutionary and Therapeutic Implications. PLoS ONE 2015, 10, e0139001. [CrossRef]

47. Shaw, A.N.; Tedesco, R.; Bambal, R.; Chai, D.; Concha, N.O.; Darcy, M.G.; Dhanak, D.; Duffy, K.; Fitch, D.M.; Gates, A.; et al. Substituted benzothiadizine inhibitors of Hepatitis C virus polymerase. Bioorganic Med. Chem. Lett. 2009, 19, 4350-4353. [CrossRef] [PubMed]

48. Abdurakhmanov, E.; Solbak, S.M.Ø.; Danielson, U.H. Biophysical Mode-of-Action and Selectivity Analysis of Allosteric Inhibitors of Hepatitis C Virus (HCV) Polymerase. Viruses 2017, 9, 151. [CrossRef]

49. Saalau-Bethell, S.M.; Woodhead, A.J.; Chessari, G.; Carr, M.G.; Coyle, J.; Graham, B.; Hiscock, S.D.; Murray, C.W.; Pathuri, P.; Rich, S.J.; et al. Discovery of an allosteric mechanism for the regulation of HCV NS3 protein function. Nat. Methods 2012, 8, 920-925. [CrossRef]

50. Kim, Y.; Jedrzejczak, R.; Maltseva, N.I.; Wilamowski, M.; Endres, M.; Godzik, A.; Michalska, K.; Joachimiak, A. Crystal structure of Nsp15 endoribonuclease NendoU from SARS-CoV -2. Protein Sci. 2020, 29, 1596-1605. [CrossRef]

51. Ricagno, S.; Egloff, M.-P.; Ulferts, R.; Coutard, B.; Nurizzo, D.; Campanacci, V.; Cambillau, C.; Ziebuhr, J.; Canard, B. Crystal structure and mechanistic determinants of SARS coronavirus nonstructural protein 15 define an endoribonuclease family. Proc. Natl. Acad. Sci. USA 2006, 103, 11892-11897. [CrossRef] [PubMed]

52. Decroly, E.; Debarnot, C.; Ferron, F.; Bouvet, M.; Coutard, B.; Imbert, I.; Gluais, L.; Papageorgiou, N.; Sharff, A.; Bricogne, G.; et al. Crystal structure and functional analysis of the SARS-coronavirus RNA cap 2'-o-methyltransferase nsp10/nsp16 complex. PLoS Pathog 2011, 7, e1002059. [CrossRef]

53. Zhang, L.; Li, L.; Yan, L.; Ming, Z.; Jia, Z.; Lou, Z.; Rao, Z. Structural and Biochemical Characterization of Endoribonuclease Nsp15 Encoded by Middle East Respiratory Syndrome Coronavirus. J. Virol. 2018, 92, e00893-18. [CrossRef] [PubMed]

54. Hodel, A.E.; Gershon, P.D.; Quiocho, F.A. Structural basis for sequence-nonspecific recognition of 5'-Capped mRNA by a cap-modifying enzyme. Mol. Cell. 1998, 1, 443-447. [CrossRef]

55. Aminjafari, A.; Ghasemi, S. The possible of immunotherapy for COVID-19: A systematic review. Int. Immunopharmacol. 2020, 83, 106455. [CrossRef] 
56. Fan, H.-H.; Wang, L.-Q.; Liu, W.-L.; An, X.-P.; Liu, Z.-D.; He, X.-Q.; Song, L.-H.; Tong, Y.-G. Repurposing of clinically approved drugs for treatment of coronavirus disease 2019 in a 2019-novel coronavirus-related coronavirus model. Chin. Med. J. 2020, 133, 1051-1056. [CrossRef] [PubMed]

57. Wu, C.; Liu, Y.; Yang, Y.; Zhang, P.; Zhong, W.; Wang, Y.; Wang, Q.; Xu, Y.; Li, M.; Li, X.; et al. Analysis of therapeutic targets for SARS-CoV-2 and discovery of potential drugs by computational methods. Acta Pharm. Sin. B 2020, 10, 766-788. [CrossRef] [PubMed]

58. Waterhouse, A.; Bertoni, M.; Bienert, S.; Studer, G.; Tauriello, G.; Gumienny, R.; Heer, F.T.; Beer, T.A.P.D.; Rempfer, C.; Bordoli, L.; et al. SWISS-MODEL: Homology modelling of protein structures and complexes. Nucleic Acids Res. 2018, 46, W296-W303. [CrossRef]

59. Camacho, C.; Coulouris, G.; Avagyan, V.; Ma, N.; Papadopoulos, J.; Bealer, K.; Madden, T. BLAST+: Architecture and applications. BMC Bioinform. 2009, 10, 421. [CrossRef]

60. Remmert, M.; Biegert, A.; Hauser, A.; Soeding, J. HHblits: Lightning-fast iterative protein sequence searching by HMM-HMM alignment. Nat. Methods 2011, 9, 173-175. [CrossRef]

61. Xu, J.; Jiao, F.; Berger, B. A tree-decomposition approach to protein structure prediction. Proceedings of 2005 IEEE Computational Systems Bioinformatics Conference (CSB'05), Stanford, CA, USA, 8-12 August 2005; IEEE Computer Society Press: Los Alamitos, CA, USA; pp. 247-256. [CrossRef]

62. Krivov, G.G.; Shapovalov, M.V.; Dunbrack, R.L.; Dunbrack, R.L. Improved prediction of protein side-chain conformations with SCWRL4. Proteins Struct. Funct. Bioinform. 2009, 77, 778-795. [CrossRef]

63. Eastman, P.; Swails, J.; Chodera, J.D.; McGibbon, R.T.; Zhao, Y.; Beauchamp, K.A.; Wang, L.-P.; Simmonett, A.C.; Harrigan, M.; Stern, C.D.; et al. OpenMM 7: Rapid development of high performance algorithms for molecular dynamics. PLoS Comput. Boil. 2017, 13, e1005659. [CrossRef] [PubMed]

64. Jr, A.D.M.; Feig, M.; Brooks, C.L. Extending the treatment of backbone energetics in protein force fields: Limitations of gas-phase quantum mechanics in reproducing protein conformational distributions in molecular dynamics simulations. J. Comput. Chem. 2004, 25, 1400-1415. [CrossRef]

65. Benkert, P.; Biasini, M.; Schwede, T. Toward the estimation of the absolute quality of individual protein structure models. Bioinformatics 2010, 27, 343-350. [CrossRef]

66. Studer, G.; Rempfer, C.; Waterhouse, A.M.; Gumienny, R.; Haas, J.; Schwede, T. QMEANDisCo-distance constraints applied on model quality estimation. Bioinformatis 2020, 36, 1765-1771. [CrossRef] [PubMed]

67. Heo, L.; Feig, M. Modeling of Severe Acute Respiratory Syndrome Coronavirus 2 (SARS-CoV-2) Proteins by Machine Learning and Physics-Based Refinement. bioRxiv. Preprint. 2020. [CrossRef]

68. Phillips, J.C.; Braun, R.; Wang, W.; Gumbart, J.; Tajkhorshid, E.; Villa, E.; Chipot, C.; Skeel, R.D.; Kale, L.; Schulten, K. Scalable molecular dynamics with NAMD. J. Comput. Chem. 2005, 26, 1781-1802. [CrossRef] [PubMed]

69. Stewart, J.J.P. Optimization of parameters for semiempirical methods VI: More modifications to the NDDO approximations and re-optimization of parameters. J. Mol. Model. 2012, 19, 1-32. [CrossRef]

70. Pedretti, A.; Villa, L.; Vistoli, G. VEGA-An open platform to develop chemo-bio-informatics applications, using plug-in architecture and script programming. J. Comput. Mol. Des. 2004, 18, 167-173. [CrossRef]

(C) 2020 by the authors. Licensee MDPI, Basel, Switzerland. This article is an open access article distributed under the terms and conditions of the Creative Commons Attribution (CC BY) license (http://creativecommons.org/licenses/by/4.0/). 